\title{
Improving and embedding project management practice in organisations - A qualitative study
}

\author{
Gabriela Fernandes $^{\mathrm{a}, *}$, Stephen Ward ${ }^{\mathrm{b}, 1}$, Madalena Araújo ${ }^{\text {a,2 }}$ \\ ${ }^{a}$ University of Minho, Campus de Azurém, 4800-058 Guimarães, Portugal \\ ${ }^{\mathrm{b}}$ University of Southampton, Highfield, Southampton SO17 1BJ, United Kingdom
}

Received 16 September 2014; received in revised form 7 January 2015; accepted 15 January 2015

Available online 26 February 2015

\begin{abstract}
This paper describes the results of a qualitative study to develop a framework to help organisations to embed useful project management improvement initiatives (PMIIs), which specifically aimed to identify key PMIIs and key embedding factors, based upon the circumstances encountered in different organisations. While the literature on PM provides some advice about PMIIs, understanding how to facilitate their embedment appears to be limited. However, research reported in the innovation literature provides a useful preliminary set of salient factors. A first attempt at framework conceptualisation based on a literature review was used as a starting point for exploratory empirical research. A series of thirty semi-structured interviews with PM professionals sought to identify additional PMIIs and embedding factors and check its salience. Analysis of the interviews data led to a framework comprising key 15 PMIIs and 26 key embedding factors, grouped into four improving themes and six embedding themes.
\end{abstract}

(C) 2015 Elsevier Ltd. APM and IPMA. All rights reserved.

Keywords: Improving; Embedding; Project management practice

\section{Introduction}

In the past thirty years project management (PM) has developed substantially as a discipline and significantly increased in visibility and importance (Kwak and Anbari, 2009; Mir and Pinnington, 2014; Zhai et al., 2009). Business is becoming increasingly 'projectised' or project oriented (Martinsuo et al., 2006), and 'management by projects' has become a powerful way to integrate organisational functions and motivate groups to achieve higher levels of performance and productivity (Morris, 1997). Nevertheless, achieving effective PM remains a challenge.

The Standish Group International (2009) found that, in the year 2008 , only $32 \%$ of all the projects surveyed succeeded (i.e. were delivered on time, on budget, with the required features

\footnotetext{
* Corresponding author. Tel.: +351 224093808, +351 253510343.

E-mail addresses: g.fernandes@dps.uminho.pt (G. Fernandes),

scw@soton.ac.uk (S. Ward),mmaraujo@dps.uminho.pt (M. Araújo).

${ }^{1}$ Tel.: +44 2380592556, +44 2380593844.

${ }^{2}$ Tel.: +351 253510344, +351253510343.
}

and functions); $44 \%$ were challenged (late, over budget and/or with less than the required features and functions) and $24 \%$ of projects failed (cancelled prior to completion or delivered and never used). These results highlight the importance of improving PM practice in organisations. Geraldi et al. (2008) raised the question of how to better develop and apply the knowledge of PM in projects. Cooke-Davies (2001) has studied a similar research question "What can be done to improve PM practices, and thus project performance?" As argued by Shi (2011), how to implement and improve PM in the 'right way' remains a relevant research topic.

There are a large number of ways in which organisations can improve PM practice (Thomas and Mullaly, 2008). For example, the implementation of PM methodologies varies considerably, from very ad hoc and informal approaches, to methodologies that are formally defined and consistently adhered to. Different strategies are employed for training and employee development, namely through the implementation of PM career paths or PM certification systems. There are different approaches adopted in introducing project support 
groups (such as PM offices), and these support groups differ in focus, structure and influence (Hobbs et al., 2008).

In an attempt to indicate a "best" path to improve PM, Shi (2011) has proposed a Value Adding Path Map (VAPM) approach directing an organisation step by step to introduce and implement PM in a better way. Shi (2011) argues that it is the coordination of the 'hard' and 'soft' PM system implementations that creates the largest value to an organisation with the least investment. The 'hard' PM system means the traditional ways of PM implementation, which includes the PM process, PM training and knowledge management and PM tools and techniques. The 'soft' PM system includes general management systems and 'PM culture'. While Shi's study makes a recommendation of the "best" path to implement PM, the idea that effective PM practice can vary from one organisational context to another is widely accepted (Besner and Hobbs, 2013; Cooke-Davies et al., 2009; Thomas and Mullaly, 2008).

For example, organisations might use PM maturity models (Project Management Institute, 2013; Sowden et al., 2010), to understand the current capability to undertake PM, and to help them to improve PM practice in a structured way (Sowden et al., 2010). Unfortunately, no one model has achieved general acceptance, and from a practical perspective maturity models have a large number of indicators which make it hard to direct an organisation to improve PM practice (Shi, 2011). Therefore, while the literature on PM provides some advice, organisations need guidance on which key project management improvement initiatives (PMIIs) they should concentrate their efforts (Shi, 2011; Thomas and Mullaly, 2008).

In this research study, PMIIs include not just specific tools and techniques, or enhancements of tools and techniques, but also processes, set of behaviours, routines, and ways of working, that are directed at improving project management performance.

Surprisingly, the PM literature seems to have given little attention to the problem of embedding PMIIs in organisations, tending to focus on what to improve and not so much on how to establish and maintain the improvements.

The concept of embedding appears to be discussed mainly in knowledge management literature. Argote et al. (2003) argue that the process of embedding of knowledge is one of the most fundamental areas in knowledge management and organisational learning research. Knowledge is said to be embedded, when it is deeply transferred or integrated into people's interpretive frameworks, routines and work practices (Cranefield and Yoong, 2009). However, Cranefield and Yoong (2009, p 259) have argued that "the nature of the knowledge embedding process is not well understood at either the organisational or the individual level. In the research literature there is neither clarity about how embedding occurs, nor a good understanding of how it can be facilitated".

Different perspectives to address the problem of embedding PM practice could be employed, such as knowledge management, organisational learning, and change management. However, typical concepts in these perspectives do not seem to provide sufficient practical guidance to PM professionals in embedding PMIIs. However, the research literature on innovation literature offers potentially relevant insights employing concepts of diffusion, dissemination, implementation and routinisation, particularly from the areas of information and technology and health care services (Greenhalgh et al., 2004; Venkatesh and Bala, 2008). Therefore, to explore embedment of a PMII in organisations, the research reported here conceptualises PMIIs as innovations in order to develop an understanding of the process of embedding PMIIs.

This research interprets several key concepts as follows:

- Diffusion is considered as the passive spread of innovations (i.e. a passive phenomenon of social influence).

- Dissemination involves active and planned efforts to convince target groups to adopt an innovation.

- Implementation of an innovation is here viewed as active and planned efforts to mainstream the innovation within an organisation.

- Routinisation is seen as the institutionalisation of an innovation and its standard use within an organisation (Greenhalgh et al., 2004).

Therefore, embedding PMIIs is studied as a process rather than an event, with PMII embeddedness into the organisation as the result (i.e. adopted by all relevant individuals and incorporated into "business as usual").

Van de Ven et al. (1999) argue that at the organisational level, the move from considering an innovation to successfully routinizing it is generally a nonlinear process characterised by multiple shocks, setbacks, and unanticipated events. The various influences that help the innovation spread through the organisation can be thought of as lying on a continuum between pure diffusion and active dissemination (Greenhalgh et al., 2004). In this study the diffusion and dissemination of PMIIs is regarded as a process of 'communication and influence' for the adoption decision of the PMII by the organisation. The characteristics of an innovation (PMII) and the individual adopters have particular influence in this process (Rogers, 2003). As argued by Greenhalgh et al. (2004, p 598) "people are not passive recipients of innovations. Rather (and to a greater or lesser extent in different persons), they seek innovations, experiment with them, evaluate them, find (or fail to find) meaning in them, develop feelings (positive or negative) about them, challenge them, worry about them, complain about them, "work around" them, gain experience with them, modify them to fit particular tasks, and try to improve or redesign themoften through dialogue with other users".

Implementation is the efforts made to introduce the use of a PMII in the organisation. As argued by Meyers et al. (1999, p 295) implementation is "the early usage activities that often follow the adoption decision". The PMII implementation and routinisation success are dependent on the organisation context (e.g. Cooke-Davies et al., 2009). Different organisations provide widely differing contexts for innovations, and some features of organisations (both structural and "cultural") have been shown to influence the likelihood that an innovation will be successfully embedded (Nystrom et al., 2002; Sharma and Rai, 2003). Additionally, external influences can also have 
some effect (Abrahamson and Fairchild, 1999; Johnston and Linton, 2000).

Therefore in this paper, the factors that might have influence in the different stages of the embedding process (diffusion, dissemination, implementation and routinisation), such as characteristics of the inner and outer contexts of the organisation, the adopters, and the innovations (PMIIs) attributes, will be regarded as factors that could facilitate or inhibit the embedding process of PMIIs.

In the innovation literature the term 'adopting' is commonly used instead of the term 'embedding' used in this study. The term 'embedding' is used here to reflect an organisational, rather than individual adopter perspective. Most of the research on diffusion of innovation focuses on product-based innovations, for which the unit of adoption is the individual (Rogers, 2003), whereas the unit of adoption in this study is the organisation. Rogers (2003) defines adoption (in relation to the individual) as the decision to make full use of the innovation as the best course of action available, and presents an individual's adoption as having five stages: awareness, persuasion, decision, implementation, and confirmation. However, empirical work in the field of organisation and management clearly shows that successful individual adoption is only one component of the assimilation of complex innovations in organisations (Greenhalgh et al., 2004). Individuals in the organisation can adopt a PMII, but this does not mean that the PMII is embedded in the organisation. It is only the routine use of the PMII and the strong contextualisation (customisation) and integration with other contextualised management practices in the organisation, and the sense of 'ownership' facilitated by the staff involvement at all levels, that result in PMII embeddedness in the organisation (Greenhalgh et al., 2004).

In the PM literature, authors use to focus their research on the PM implementation process, assuming simply that there is always a successful implementation, which implies the routinisation of its use. However, an organisation can make efforts towards improvements yet not achieve the improvement embeddedness.

This paper examines the problem of improving and embedding PM practice using a 'success factor' approach, and identifies a set of key PMIIs and factors that can facilitate the embedding of these initiatives in organisations, based on empirical work.

Summarising the above discussion, effective PM is crucial to survival for many companies in a fast changing environment (Ebert and Man, 2008), but there is insufficient understanding of how to improve and embed PM practice. Organisations need more guidance on which PMIIs they should concentrate their efforts and how to facilitate the embedment of PMIIs into their systems. The research reported here is an attempt to provide such guidance.

\section{Research conceptualisation}

This research reported here is conceptualised into two constructs, practices that will: improve PM termed PM improvement initiatives (PMIIs) and embedding PMIIs. The two concepts are linked as indicated in Fig. 1, since an organisation engaged in embedding a PMII is consequently improving PM practice. However, in this research 'improving' is seen as the identification and selection of useful PMIIs that then need embedding into the organisation. Therefore, with respect to the improving construct, the research work focused on identifying the most useful PMIIs, such as the standardisation of PM processes, tools and techniques. In respect of the embedding construct, the research focused on identifying factors contributing to the successful embeddedness of PMIIs. The assumption is that if an organisation is aware of these factors and addresses them during the stages of the embedment process of a PMII, then the embeddedness is more likely to be achieved.

A basic assumption of this research is that improving PM practice improves project and organisational performance, even if the actual value resulting from investments in PM has been hard to define and measure (Thomas and Mullaly, 2008). In order to maximise the value of PM, two things should be addressed. Firstly, the identification of appropriate PMIIs, both strategic and tactical (Shi, 2011; Winter and Szczepanek, 2008); and secondly, implementation processes should fit the organisational context (Cooke-Davies et al., 2009; Shi, 2011; Thomas and Mullaly, 2008; Zhai et al., 2009).

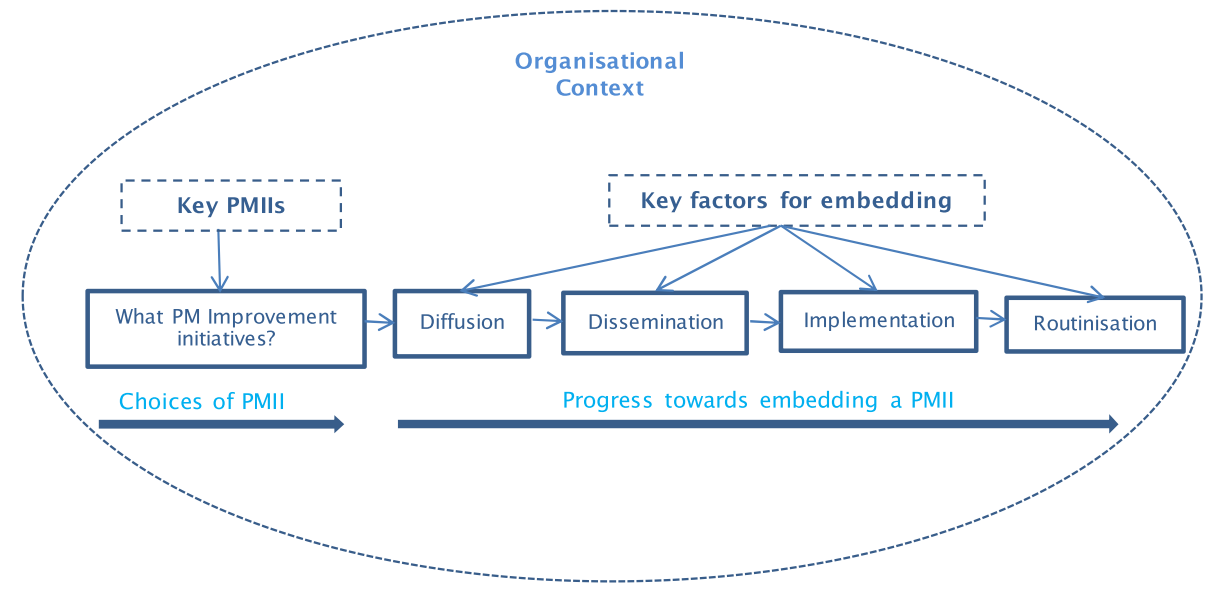

Fig. 1. Research conceptualisation. 
The research described in this paper aims to make some contribution in this field by developing a framework to help organisations to embed useful PMIIs. The framework identifies:

1) which PMIIs are regarded as most useful and therefore need to be embedded; and

2) the key factors that can facilitate the embedding of these initiatives into PM practice.

In the development of the framework, it was necessary to make some judgments about how far to distinguish between different embedding factors and the range of PMIIs. This 'decomposition problem' arises in most areas of management analysis. For example, in the analysis of sources of project uncertainty and risk, Chapman and Ward (2011, p 32) argue that "...even the most decomposed structures which are viable still involve low level composites. Further decomposition to clarify a source [of uncertainty] may be possible, but in practice the limits to decomposition will be defined by what is useful. Further, the most effective and efficient decomposition structure is a matter of choice which is necessarily dependent upon the process objectives".

In this initial study reasonably high abstraction level descriptions were adopted. For example the PMII 'standardisation of PM processes', was employed rather than distinguishing different kinds of PM processes.

The results presented here are part of a broader research study on improving and embedding PMII with other objectives: (1) to identify the most useful PMII practices (reported in the article by Fernandes, Ward and Araújo, 2013); (2) the identification of the inter-relationships between the key PMIIs and key factors to facilitate embedment of these initiatives; and (3) to find if respondents from different organisational contexts in the study identify different relevance levels of the key PMIIs and the key factors to facilitate their embedment.

\section{Development of an 'initial framework' from a literature review}

Based on a review of the normative literature, a first attempt to construct a conceptual framework, listing the PMIIs regarded as most useful and the key factors that can facilitate the embedding of the PMIIs into PM practice, drew largely from three main theoretical foundations:

- The Value Adding Path Map (VAPM) framework from Shi (2011), which identifies several improvement initiatives, identifying them as 'hard' and 'soft' PM system

Table 1

Useful project management improvement initiatives.

\begin{tabular}{|c|c|}
\hline Themes & Key PMIIs \\
\hline $\begin{array}{l}\text { Process, tools, and } \\
\text { techniques }\end{array}$ & $\begin{array}{l}\text { 1. 'Implement standardized PM processes.' Several PM bodies of knowledge and methodologies offer guidance on such matters } \\
\text { (Andersen and Vaagaasar, 2009; Loo, 2002; Milosevic and Patanakul, 2005; Shi, 2011; Thomas and Mullaly, 2008). } \\
\text { 2. 'Implement standardized PM tools and techniques' (Anantatmula, 2008; Milosevic and Patanakul, 2005; Shi, 2011; Thomas and } \\
\text { Mullaly, 2008). }\end{array}$ \\
\hline $\begin{array}{l}\text { People and organisational } \\
\text { learning }\end{array}$ & $\begin{array}{l}\text { 3. 'Manage PM competences,' for example, by assessing PM competencies of people from different PM roles, and providing PM } \\
\text { training (Andersen and Vaagaasar, 2009; Loo, 2002; Shi, 2011; Thomas and Mullaly, 2008). } \\
\text { 4. 'Established PM career path for all PM roles' in order to motivate people to improve in their PM practice to climb the PM career path } \\
\text { (Cooke-Davies et al., 2009; Shi, 2011). } \\
\text { 5. 'Develop a culture of learning' in order to better enhance the PM knowledge created in the organisation (Loo, 2002; Burnes et al., } \\
\text { 2003; Atkinson et al., 2006; Sense, 2007; Shi, 2011). }\end{array}$ \\
\hline $\begin{array}{l}\text { General management } \\
\text { system }\end{array}$ & $\begin{array}{l}\text { 6. 'Integration of the PM system with the general management system,' i.e., the alignment of PM activities with the whole } \\
\text { organisation's activities. For example, the strategic planning of the organisation should be tightly coupled with the project identification } \\
\text { and prioritization (Meskendahl, 2010; Milosevic and Srivannaboon, 2006; Shi, 2011). } \\
\text { 7. 'Develop supported infrastructure,' i.e. a PM office or a similar structure (Dai and Wells, 2004; Hobbs et al., 2008; Pellegrinelli and } \\
\text { Garagna, 2009; Shi, 2011). } \\
\text { 8. 'Develop a project sympathetic organisation structure to PM,' for example, a projectized structure or a strong matrix structure } \\
\text { (Maylor et al., 2006; Martinsuo et al., 2006; Shi, 2011). } \\
\text { 9. 'Empowerment of project managers' the organisation should ensure that project managers have sufficient authority when managing } \\
\text { projects and that project managers are highly respected in the organisation (Maylor et al., 2006; Loo, 2002; Shi, 2011; Thomas and } \\
\text { Mullaly, 2008). } \\
\text { 10. 'Develop a project categorisation system' in order to tailor the PM processes, tools, and techniques to the different types of projects } \\
\text { in the organisation (Crawford and Pollack, 2004; Crawford et al., 2006; Malach-Pines et al., 2009). } \\
\text { 11. 'Benchmarking to Assess PM and continuous improvement' through for example, the use of a model from the literature to assess the } \\
\text { current capability of the organisation to undertake PM to define what may be needed to make the organisation more capable in PM } \\
\text { terms (Barber, 2004; Luu et al., 2008). } \\
\text { 12. 'Assessment of project management performance' the feedback to PM team members of the project management performance } \\
\text { assessment, during the project's life cycle (Qureshi et al., 2009). }\end{array}$ \\
\hline PM culture & $\begin{array}{l}\text { 13. 'Develop awareness of the project value' to project and organisation performance among all staff members (Thomas and Mullaly, } \\
\text { 2008; Zhai et al., 2009). } \\
\text { 14. 'Develop a basic understanding of organisational PM practices among all project stakeholders' (Shi, 2011; Thomas and Mullaly, } \\
\text { 2008). } \\
\text { 15. 'Establish PM practices as internal standards' (Andersen and Vaagaasar, 2009; Eskerod and Riis, 2009; Shi, 2011; Thomas and } \\
\text { Mullaly, 2008). }\end{array}$ \\
\hline
\end{tabular}


implementations, and inclusively gives the indication of step by step to introduce them in the organisation in a better way.

- The conceptual model for the spread and sustainability of innovation in service delivery and organisation from Greenhalgh et al. (2004), which is the result of one of the most comprehensive reviews of research on innovations, and had as the unit of adoption the organisation and not just individuals, which is the focus of this research. Greenhalgh's model identifies several factors for the spread and sustainability of innovation grouped into six main themes: i) PMII (innovation) attributes; ii) adopter and adoption process by individuals; iii) communication and influence (diffusion/ dissemination); iv) inner context; v) outer context; and vi) implementation.

- The technology acceptance model3 (TAM3) from Venkatesh and Bala (2008), which is a combination of the model of the determinants of 'perceived ease of use' from Venkatesh (2000) and TAM2, which presents the determinants of 'perceived usefulness' (Venkatesh and Davis, 2000).

\subsection{Useful PM improvement initiatives}

The literature review first sought to identify a number of PMIIs beyond the implementation of specific tools and techniques, which have the greatest impact on improving PM practice. Table 1 presents a summary of the key PMIIs, which were then included in the 'initial framework' for improving PM practice.

The VAPM framework was particularly useful for this research. The VAPM was based on the research findings of Thomas and Mullaly (2008) entitled "Researching the Value of Project Management," a three-year study, involving a multi-disciplinary research team, with over 45 academics and 65 organisations worldwide from very different contexts. Additionally, Shi (2011) interviewed $30 \mathrm{PM}$ practitioners from a variety of Chinese industrial sectors and applied the framework to a case study, which shows that this approach is simple and easy to use.

Following the classification by Shi (2011), these key initiatives were grouped under the following themes:

1. Process, tools and techniques

2. People and organisational learning

3. General management system and

4. PM culture.

\subsection{Key embedding factors}

The conceptual model for the spread and sustainability of innovation in service delivery and organisation from Greenhalgh et al. (2004), and the technology acceptance model3 (TAM3) from Venkatesh and Bala (2008) were selected as the main theoretical foundation for the embedding construct. These two works were not only selected for reasons associated with the similarity of objectives, robustness, empirical evidence obtained, multidisciplinary teams and multitude of organisational contexts (Greenhalgh model), but also due to the relevance of the variables being used, namely 'perceived usefulness' and 'perceived ease of use' (TAM3).

Through literature review a number of key factors and six themes were identified which might have greatest impact on embedding PMIIs. Table 2 presents a summary of the key embedding factors identified.

In terms of the embedding process, different factors might assume a higher or a lower influence through diffusion, dissemination, implementation to routinisation. The key embedding factors associated with themes of 'PMII (innovation) attributes', 'adopter and adoption', 'inner context' and 'outer context' might have influence during the whole embedding process. However, the factors related to 'communication and influence' would have more influence during the diffusion and dissemination stages, and the factors related to 'implementation' would have more influence during the implementation stage. For example, an organisation that wants to embed a systematic process to progress reporting using the earned value management (EVM) technique, would start, in the 'communication and influence' (diffusion/dissemination) stage, concentrating efforts to create awareness of the value of the EVM technique, and gathering information about the technique needs to be disseminated; in the implementation stage, training on the concept and use of the technique may be necessary. Over time, in the routinisation stage, the organisation would evaluate and communicate the impact of the use of EVM technique to project management performance.

Under the theme 'implementation', several factors were identified; however, these factors are also related to other themes, for example 'resources to support change' identified under the theme 'inner context' or the 'feedback on the PM improvement impacts' identified under the theme 'communication and influence.' The literature on the routinisation of innovations was very sparse and parenthetically linked to the theme 'implementation' (Greenhalgh et al., 2004), and so as a result, the direct key embedding factors related to 'routinisation' were not identified from literature review.

\section{Research methodology}

There is no single theory existing today that comprehensively explains how to improve and embed PM practice (Cranefield and Yoong, 2009; Shi, 2011). In fact, how to improve PM is very dependent on the organisational context (Besner and Hobbs, 2008, 2013; Cooke-Davies et al., 2009). As a result, this research cannot simply be about conclusively testing a single theory, but instead must emphasise the generation of theory based upon actual findings and data. Therefore, an exploratory research was undertaken, which aimed to identify key PMIIs and key factors for embedding PMIIs, based upon the circumstances encountered in different organisations. The analysis was guided by an inductive perspective, whereby the collection, examination and process of continual re-examination of data determined the research findings (Robson, 2002). An initial attempt at framework conceptualisation based on a literature review was used to guide a subsequent empirical exploratory study. 
Table 2

Key embedding factors.

\begin{tabular}{|c|c|}
\hline Theme & Key embedding factors \\
\hline Project management improvement & 1. 'Clear relative advantage' (Greenhalgh et al., 2004; Rogers, 2003). \\
\hline
\end{tabular}
2003).

3. 'Simple rather than complex to deploy' (Greenhalgh et al., 2004; NHS Modernisation Agency, 2003; Rogers, 2003).

4. 'Trialability.' PM improvements that can be experimented with by intended users on a limited basis will be more easily embedded (Greenhalgh et al., 2004; Rogers, 2003).

5. 'Observability' visibility of benefits (Greenhalgh et al., 2004; Rogers, 2003).

6. 'Re-invention' - capable of adaptation, refinement or modification (Greenhalgh et al., 2004; Rogers, 2003).

7. 'Low uncertainty about outcomes' (Greenhalgh et al., 2004; Szulanski, 1996, 2000).

8. 'Proven track record' (Szulanski, 1996, 2000).

Adopter and adoption process

9. 'Adopter motivation'. Adopters need to be convinced that PM activity will help them to meet their objectives in a cost effective manner, both directly and indirectly through enhanced organisational performance (Greenhalgh et al., 2004; Ward, 2004).

10. 'Perceived usefulness'. The Technology Acceptance Model (TAM3) posits that adopter acceptance is determined by only this key factor or adopter's belief and the next one (Venkatesh and Bala, 2008).

11. 'Perceived ease of use' (Venkatesh and Bala, 2008).

12. 'Beliefs of similarity or difference from other adopters' (Bresnen and Marshall, 2001).

13. 'Gender and age differences' (Morris and Venkatesh, 2000; Venkatesh et al., 2004).

14. 'Nature of adoption decision' which could be optional, collective, authoritative or contingent (Greenhalgh et al., 2004; Rogers, 2003).

Communication and influence

15. 'Demonstrating the PMII value.' Effective communication of the value of the PMII across structural boundaries within the organisation prior to its implementation (Greenhalgh et al., 2004; Venkatesh and Bala, 2008).

16. 'Homophily.' The adoption of a PMII by individuals is more likely if they are homophilous, in other words, if the members involved in the process of change are similar in certain attributes (Greenhalgh et al., 2004; NHS Modernisation Agency, 2003; Rogers, 2003).

17. 'Interpersonal channels.' In communication mass media are important for creating awareness, but 'interpersonal channels' are vastly more influential (Greenhalgh et al., 2004). The embedment of PM improvements by individuals is powerfully influenced by the structure and quality of their social network (NHS Modernisation Agency, 2003; Rogers, 2003).

18. 'Opinion leaders.' The existence of influencers who can encourage the take up and embedment of PMIIs (Englund and Bucero, 2006; Greenhalgh et al., 2004; Loo, 2002; NHS Modernisation Agency, 2003; Rogers, 2003).

19. 'Use of rhetoric' to give a strong compelling and sustained motive for embedding a PMII (Green, 2004).

20. 'Adopter involvement' earlier in the implementation process (Burnes, 2004; Eskerod and Riis, 2009; Greenhalgh et al., 2004; NHS Modernisation Agency, 2003).

21. 'Motivation of knowledge holders.' If the source has fear of losing ownership of the knowledge, they would not be motivated to support the effective embedment of the PMII (Szulanski, 1996).

22. 'Credibility of the source of the knowledge,' i.e., credible and trusted change agents (Greenhalgh et al., 2004; Szulanski, 1996).

23. 'Relationship between the source of the knowledge and the adopter,' i.e., stability and trust in the relationship between change agents and adopters (Greenhalgh et al., 2004; Szulanski, 1996).

24. 'Feedback on improvement impacts in the project and organisation performance (Greenhalgh et al., 2004).

Inner context

25. 'Structure and resources to support change' (Greenhalgh et al., 2004; Loo, 2002; NHS Modernisation Agency 2003).

26. 'Absorptive capacity for new knowledge.' Organisations with a learning organisation culture and a proactive leadership directed toward sharing knowledge are more likely to adopt and embed PM improvements (Greenhalgh et al., 2004; Szulanski, 1996, 2000).

27. 'Receptive context for change.' With features such as strong leadership and support (Englund and Bucero, 2006; Loo, 2002; Kerzner, 2009; Nystrom et al., 2002; Sharma and Rai, 2003), clear strategic vision, good managerial relations, visionary staff in key positions, a climate conducive to experimentation and risk-taking (Greenhalgh et al., 2004).

28. 'Readiness for change' (Greenhalgh et al., 2004; NHS Modernisation Agency, 2003).

Outer context

29. 'Informal interorganisational networks.' An important influence on an organisation's decision to adopt is whether a threshold proportion of comparable (homophilous) organisation's have implemented or plan to implement improvement initiatives (Carayon, 2010; Greenhalgh et al., 2004; Johnston and Linton, 2000).

30. 'External mandates' (political 'must-dos') increase the predisposition, which is the motivation of an organisation to adopt a new PM practice (Greenhalgh et al., 2004).

Implementation

31. 'Effective change agents' (Greenhalgh et al., 2004; Rogers, 2003).

32. 'Specific training' in associated new tasks and working methods (Carayon, 2010, Loo, 2002).

A new PM practice is unlikely to deliver desired results if it does not 'fit' within the organisation or its competitive environment (Cooke-Davies et al., 2009). In order to address this issue, the overall research study sought to understand how the set of key PMIIs and key factors to embed PMIIs might vary in different organisational contexts, namely: industry, size and project type (out of scope of this paper). Therefore, the identification of potential companies to participate on the semi-structured interviews phase was based on three criteria:

1. prior knowledge the researcher had about some organisations due to previous work contacts; 
2. the type of industry; and

3. the size of the companies (the research adopted the classification of companies size from the European Commission).

Additionally, given the exploratory nature of this research study, the empirical data needed to cover different sectors of activity and organisation size in order to reduce the risk of getting only a narrow view on the issue of improving and embedding PM practice in organisations.

Twenty one organisations were identified as potential firms to participate in the semi-structured interview research phase, to which the researchers tried to gain access. Due to budget and time restrictions and personal privileged access, only Portuguese organisations were identified for interviews. Although there was some difficulty in getting agreement from organisations to participate in the study (several contacts had to be done before starting to get some positive answers), semi-structured interviews were carried out in seven different organisations (different industries, sizes and project types). The sample was considered a fair representation of Portuguese industry, with three small, two medium and two large companies participating, which reflects the industry structure in Portugal (SMEs account for more than 99\% of companies operating in Portugal).

The selection of only Portuguese organisations to participate in the study may raise a question of data bias, because the framework was developed using interview data from a specific geographic context. However, the framework, developed from interviews with Portuguese practitioners was not dramatically different from the 'initial framework' conceptualised from literature review, suggesting that the Portuguese based framework is fairly robust.

The particular individuals selected and invited for the semi-structured interviews were involved in projects environment, in different levels of the organisational hierarchy (directors, portfolio, programme and project managers and project team members). The study did not seek to gather data from executives and project sponsors (external clients), because of the limited role and influence that such stakeholders may have on the issues of improving and embedding PM practice (Bresnen et al., 2004). The researcher explained the scope of the research study and the purpose of interviews to her direct contacts in the organisation (usually directors), and asked them to identify four or five possible participants covering the roles mentioned above, and taking into account if they are thoughtful, particularly experienced, forward thinking, and outspoken.

The empirical study involved a total of thirty semi-structured interviews with directors $(17 \%)$, portfolio and programme managers $(23 \%)$, project managers $(53 \%)$ and team members (7\%). Prior to interview all participants received by email a briefing document, which clarified the research scope, main interview questions, anonymity and confidentiality, and the key PM terms adopted by the study, in order to assure that the meanings of these terms for interviewees were consistent with the researchers' understandings. Nevertheless, each interview started with an introduction about the researcher's personal background, an outline of the research objectives and the definition of the key terms used in the interview.

Qualitative data analysis of responses was conducted in order to: (a) identify new key PMIIs and key factors for embedding PMIIs not identified in literature review, (b) get confirmation for the key PMIIs and key embedding factors identified from literature, and (c) reduce the number of PMIIs and factors identified, and build a framework with a 'manageable' number of key items, as a wide range will disperse the attention of organisations from what they should concentrate their awareness. This analysis resulted in a 'revised framework' of the 'initial framework', which consolidated a conceptualisation attempt from the literature review.

The interviews were conducted between July and September 2012. Each interview lasted between 1 and $3 \mathrm{~h}$, the average was $1 \mathrm{~h}$ and a half. Interviews were conducted in-person at the interviewee's organisation headquarters, except one that was conducted by video conference and five others by Skype call, because the interviewees spent most of their time at clients' sites.

The interview protocol consisted of the following requests to interviewees:

1) outline your experience in PM to date;

2) characterise your organisation in terms of business strategy and type of projects;

3) tell stories of organisation initiatives to improve PM in your organisation;

4) identify the most useful PM practices that you use or have used;

5) identify the most useful PMIIs, in terms of improving PM performance;

6) identify the factors that might make it easier, or more difficult, to achieve embedment of PMIIs in your organisation.

Where appropriate, supplementary questions were used to prompt more detailed responses to the above questions.

The data produced by the semi-structured interviews was collected by using tape recordings and by taking contemporaneous notes. The notes taken during the interviews were enriched after carefully listening the audio recording, and interviewees were asked to validate and possibly add to these notes if they were willing to do so. In some cases, the researcher highlighted parts of the notes that she would particularly like interviewees to check or expand upon. In the event, only $10 \%$ of the interviewees made any additions to the notes.

The data analysis was based on thematic analysis which is an appropriate technique for exploratory research and theory building purposes (Easterby-Smith et al., 2008). Thematic analysis determines the presence of themes emerging from the verbal data and deeper meaning embedded in data. Using a coding process, existing categories and relations can be searched for, quantified, and analysed to identify existing themes. Thematic analysis measures the presence and frequency of themes or concepts.

The coding process used as a basis the themes/PMIIs and embedding factors identified in the 'initial framework'. However, 


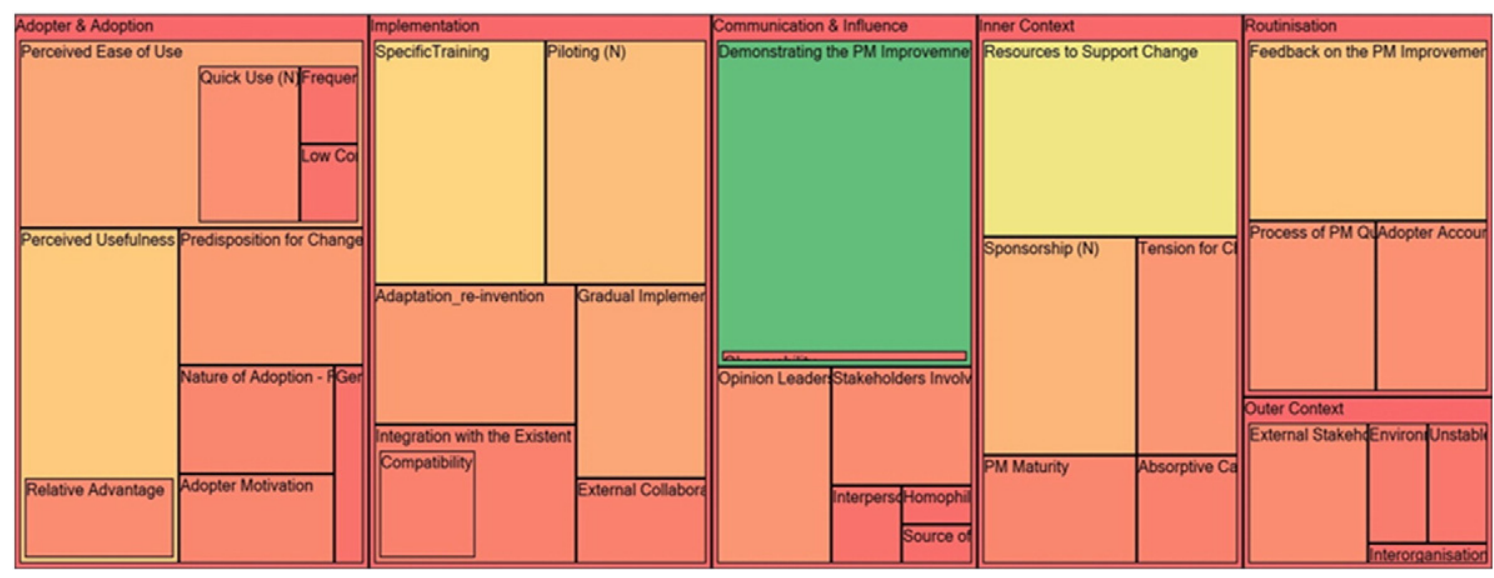

Fig. 2. Key embedding factors compared by number of items coded.

new PMIIs and embedding factors emerged and others achieved more or less significance. Through the generation of the initial codes, all the interesting features of data were systematically coded across the entire data set. Some data supported the themes/ PMIIs and embedding factors previously identified in the 'initial framework'. For example, interviewee 29 stated "it is important to assess people's PM competences, in order to identify the competences gaps and define the training plan to boost the organisation's resources and consequently PM performance". This statement was coded under the identified PMII 'Manage PM Competences'. Some data triggered a new theme/PMII and embedding factor. For example interviewee 30 observed "the 'one man show' that makes everything in the organisation, PM and a high variety of technical activities, should become extinct, and a person that dedicates her/his time to PM should appear". This statement was coded under the new PMII 'PM professionalisation'. The coding process was revisited several times, to ensure that themes identified from the literature and not identified in the interviewees' responses were effectively not implicit in the responses.

Thematic analysis can be supported by commercially available software packages. In this study Nvivo software was used. Computer-assisted counting, weighing, and theme identification processes substantially increase scoring reliability and reduce coding inconsistencies. The process results in conceptual maps presenting relevant themes, their relevance within the text, and their relationship towards each other. These maps are created using the absolute and relative count of words, categories, and terms as by the (computer-assisted) coding processes. Fig. 2 illustrates an example of a conceptual map generated by the Nvivo software, showing the relevant themes/factors ${ }^{3}$ for embedding PM practice by their relevance within the text. Larger areas indicate factors which were more frequently coded, i.e., more suggested by interviewees.

The coding process for all the 30 interviews data was performed by the same researcher. This facilitated consistency of coding. However, relying on a single researcher's

\footnotetext{
${ }^{3}$ In some rectangles of Nvivo 'map' the full text is not displayed unfortunately, Nvivo 'map' facility does not allow users to format the text inside each rectangle.
}

coding can be problematic in terms of assessing the reliability and validity of the data (Gray, 2004). To check the validity of the coding process two other researchers were asked to examine the audit trail of the key coding decisions made during the research process. Given this process, and the fact that all interviewees were asked to approve the interview notes produced, the qualitative results are considered reliable.

The empirical study relied exclusively in the data collected during the interviews. Arguably, a deeper appreciation of relevant factors in a given organisation could have been obtained by supplementing the interviews with a more extensive 'case study' based exploration of each participating organisation. Time and budget constraints, and decisions about overall research strategy precluded this more case based approach. However, in most cases the interviewer had some prior knowledge of each organisation's context, industry specifics, organisational structure and management philosophy, which facilitated deeper interviews in the time available.

\section{Results}

\subsection{The dataset}

Thirty semi-structured interviews were carried in seven Portuguese companies in different organisational contexts (industry, size and types of projects) with 3-5 interviewees in each organisation. $43 \%$ of the interviewees were from small size organisations, $30 \%$ from large, and $27 \%$ from medium sized organisations.

The sample was slightly weighted towards the Engineering and Construction sector of activity but included a sufficient number of interviewees in five different sectors:

- Engineering and construction: $30 \%$

- Information and technology: $23 \%$

- Telecommunications: $17 \%$

- Industrial services: $17 \%$

- Business services: 13\%. 
Table 3

Interviewee responses to the key PMIIs.

1. Corporate standardisation and tailoring of PM processes

2. Provide PM training

3. Corporate standardisation and tailoring of PM tools and 4. Develop a supported infrastructure

techniques

5. Manage PM competences

7. PM professionalisation

9. Develop a project sympathetic organisation structure

11. Establish PM career path for all PM roles

13. Establish PM practices as internal standards

6. Integrate the PM system with the general management system

8. Develop a culture of learning

10. Develop of PM value among all staff awareness

12. Develop a basic understanding of organisational PM practices among all project stakeholders

14. Benchmarking to PM assess and continuous improvement
Two thirds of interviewees worked on projects which vary in scope while one third worked on projects which were fairly similar in scope. Most of the interviewees, $80 \%$, were involved in projects with a high level of technical innovation, while $20 \%$ worked on projects with a low level of technical innovation. The interviews covered, in a balanced way, different project typical durations, although, most interviewees had experience of projects with durations between 3 months and 2 years. Interviewees had experience on projects covering a wide range of costs. However, the most common range varied between 50,000 and 250,000€, for $43 \%$ of the interviewees. Curiously, $10 \%$ of the interviewees did not have an idea of the projects' typical cost. This happened in two organisations where the project managers did not control the project cost, their focus was on scope, quality and time. From the researchers' professional experience, this is common in organisations with lower levels of PM maturity.

The interviewees had a high PM experience, 57\% had more than 7 years of PM experience, and appeared well qualified to provide valuable information. All had at least an undergraduate certificate, $53 \%$ of them held a graduate certification and $10 \%$ had doctorates. Most of the interviewees were male $(80 \%)$, which perhaps gives an idea of the female presence in PM area in Portugal.

\subsection{Key PM improvement initiatives}

When faced with the question about the most useful PMIIs, a large number of factors were identified by interviewees. This is not surprising, as there can be several different types of PM investments made by organisations, depending for example on the type of projects undertaken, industry, size or strategic orientation (Cooke-Davies et al., 2009; Thomas and Mullaly, 2008). The most frequent answers are listed in Table 3, by descending order of frequency.

\subsection{Key embedding factors}

The invitation to identify the factors that might make it easier or more difficult to achieve the diffusion, dissemination, implementation and routinisation, i.e. the embedment, of PMIIs in their organisation (key embedding factors), also prompted interviewees to mention a large number of factors. Table 4 summarises the most frequently identified in descending order of frequency.

\section{Discussion - development of the 'revised framework' from the interview study}

\subsection{Modifying the framework for improving PM practice}

After analysing the responses about the most useful PMIIs, the initiatives identified (Table 3 ) were compared with those initially identified from the literature review ('initial framework' Table 1). The set of initiatives in the 'initial framework' were then modified to reflect:

Table 4

Interviewee responses to the key embedding factors.

1. Demonstrating PMII value

3. Specific training

5. Feedback on the PMII impacts

7. Sponsorship

9. Gradual implementation

11. Adaptation/re-invention

13. PM quality assurance process

15. Stakeholders involvement

17. Quick use

19. Adopter motivation

21. Nature of adoption decision - mandatory

23. Integration with the existent practices

25. Environmental culture

27. Interorganisational PM practices

29. Source of the knowledge credibility

31. Interpersonal channels
2. Resources to support change

4. Perceived usefulness

6. Piloting

8. Perceived ease of use

10. Predisposition for change

12. Opinion leaders and key facilitators support

14. Adopter accountability

16. Tension for change

18. External stakeholder requirement

20. PM maturity

22. External collaboration

24. Absorptive capacity for new knowledge

26. Unstable economic environment

28. Gender differences

30. Homophily

32. Frequency of use 
- new identified PMIIs that emerged and others that achieved more significance that had been merged initially in other more general PMIIs;

- confirmed PMIIs identified from literature, although in some cases prompting some slight rephrasing to the initiative, and
- merged PMIIs into other PMIIs because interviewees did not distinguish between them.

Table 5 summarises the results, namely the \% of interviewees that prompted each PMII, highlighting if the PMIIs are confirmed or new. Most of the PMIIs were confirmed and none

Table 5

Key PMIIs in the 'revised framework'.

\begin{tabular}{|c|c|c|c|}
\hline Theme & 'Revised framework' & $\%$ & Comments \\
\hline $\begin{array}{l}\text { Process, tools, } \\
\text { and techniques }\end{array}$ & $\begin{array}{l}\text { 'Corporate standardisation and } \\
\text { tailoring of PM processes' }\end{array}$ & $93 \%$ & $\begin{array}{l}\text { Confirmed. It was the most stated PMII. This PMII was slightly rephrased to include: 1) the word } \\
\text { 'corporate', which means that the use of PM practices are not just for a specific department or } \\
\text { activity area, but are used across the organisation; and 2) the word 'tailoring'. With respect to the } \\
\text { standardisation of processes, interviewees also emphasised that PM processes should be tailored to } \\
\text { the different types of projects. This implies the development of a project categorisation system in the } \\
\text { organisation. One interviewee gives his example 'We classified your projects on type one, two, three } \\
\text { and four and the PM processes are adjusted to each project type." - (interviewee 9). } \\
\text { During the interview analysis, the researchers realised that the interviewees' concern was not the } \\
\text { projects' categorisation per se, but with the tailoring of PM process tools and techniques to different } \\
\text { projects that categorisation may facilitate. As argued by Besner and Hobbs (2008) one of the primary } \\
\text { reasons that organisations create systems for categorising projects into different types is to adapt } \\
\text { their PM methodologies (processes, tools and techniques) to the specific requirements of each type } \\
\text { of project. Therefore, the PMII identified in the initial framework 'develop project categorisation' } \\
\text { was merged with the PMIIs 'corporate standardisation and tailoring of: i) PM processes, ii) tools and } \\
\text { techniques, and iii) the project management information system (PMIS)'. }\end{array}$ \\
\hline
\end{tabular}

'Corporate standardisation and tailoring of

PM tools and techniques' 'Corporate standardisation and tailoring of project management information system (PMIS)'

People and 'Provide PM training' organisational learning 'Manage PM competences'

'Develop a culture of learning' 'PM professionalisation'

'Establish PM career path for all PM roles'

General 'Integration of the PM system with management the general management system' system 'Develop a supported infrastructure' 'Develop a project sympathetic organisation structure'

'Benchmarking to PM assess and continuous improvement'

PM culture
$80 \%$ New. The strong emphasis put by almost all interviewees, on a mechanism for storage, retrieval, dissemination, and reporting of PM information led to the separation of this PMII from the general PMII 'corporate standardisation and tailoring of PM tools and techniques'.

90\% New emerged PMII. It was the second most stated PMII. Therefore, it was separated from the more general PMII of 'manage PM competences'.

63\% Confirmed. The PMII 'assessment of PM performance' was merged in this more general PMII 'manage PM competences', because, although during literature review the researchers identified as important to define, collect, use, verify, analyse and improve PM performance criteria, and improve its visibility to the project team (Qureshi et al., 2009), the PM performance assessment was mentioned by only four interviewees, and where mentioned, it was cited in order to encourage project managers to improve their PM competences. One interviewee asserted "The problem is that the projects' KPIs are not used as input for the employee's performance assessment and career progression." - (interviewee 30 ).

$30 \%$ Confirmed.

$33 \%$ New. Interviewees affirmed the relevance of the professionalisation of the project manager's role, i.e., the project managers who dedicate almost $100 \%$ of his/her work to PM activities. Because as experienced by interviewees, when the project manager accumulates to its role, a high percentage of technical work, he/she tends to focus on the technical activities, and disregard the PM activities. PM professionalisation would be itself an interesting issue for future studies.

17\% Confirmed.

$37 \%$ Confirmed.

$63 \%$ Confirmed.

$57 \%$ Confirmed. 'Empowerment of project managers' was merged into this PMII, because this initiative is related to the organisation structure and it was highlighted by few interviewees and with minor emphasis. When empowerment was mentioned by the interviewer, some interviewees responded that this is important, but not one of the most important PMIIs.

$13 \%$ Confirmed.

$27 \%$ Confirmed.

10\% Confirmed.

'Development of a basic understanding of organisational PM practices among all project stakeholders' Establish PM practices as internal standard' 
of the PMIIs identified from literature were discredited, however some have been merged in other PMIIs.

\subsection{Modifying the framework for embedding PM practice}

After analysing the responses about key embedding factors, the results (Table 4) were compared with those initially identified on literature review ('initial framework' - Table 2). Using the same process of the improving construct, the set of the key embedding factors in the 'initial framework' were then modified to reflect:

- new identified factors that emerged and others that achieved more significance merged initially in other more general factors;

- confirmed factors identified from literature, although some warranted slight rephrasing;

- discredited factors because interviewees put slight emphasis on them; and

- merged factors into other factors because interviewees did not distinguish between them.

Table 6 summarises the results, namely the $\%$ of interviewees that prompted each embedding factor, highlighting if the factors are confirmed or new. The interview analysis led to the understanding that the first five embedding factors from Table 2: 'relative advantage', 'compatibility', 'complexity', 'trialability' and 'observability', related to the theme PMII attributes identified in diffusion literature (Greenhalgh et al., 2004; Rogers, 2003), can be regarded as components of other factors identified by interviewees. These attributes belong to a different level of factor discrimination. As mentioned in Section 2 (Research conceptualisation), from the beginning of this study, a reasonably high level of factor description was adopted. Therefore, in the 'revised framework' the theme 'PMII attributes' was removed, because it was just composed by five factors merged in other factors, two not prompted by any interviewee: 'causal ambiguity or uncertainty' and 'unproven knowledge', and one factor slightly rephrased to 'adaptation/re-invention' re-categorised under the theme 'implementation'.

A new theme was created named 'routinisation'. Two new strongly emphasised factors were raised by interviewees: 'PM quality assurance process' and 'adopter accountability'. These two factors fit in the embedding process subsequent to the implementation process, which guarantees that a PM practice will be routinely used by adopters. In the 'routinisation' theme was added the factor 'feedback on improvement impacts', identified initially under the theme "communication and influence'.

Eleven embedding factors identified from literature were 'discredited' after interview analysis, and not included in the 'revised framework'. 'Discredited' does not mean that the factor does not have influence on the embedding process, but just that the influence might be relatively minor. The following factors were just briefly mentioned (by less than $10 \%$ of the interviewees), even when supplementary questions were asked:
- 'Gender and age differences'

- 'Homophily'

- 'Interpersonal channels'

- 'Credibility of the source of the knowledge'.

For example, when the interviewer prompted the factor 'source of the knowledge credibility' interviewees agreed with its importance, but did not consider it as a key factor.

Despite careful scrutiny of responses from the interviewees, no explicit or implicit responses were found connecting the following factors identified from literature:

- 'Causal ambiguity or uncertainty'

- 'Proven track record'

- 'Beliefs of similarity or difference from other adopters'

- 'Use of rhetoric'

- 'Motivation of knowledge holders'

- 'Relationship between the source of the knowledge and the adopter'

- 'Receptive context for change'.

For example, 'proven track record' might not have been identified by interviewees because almost all PM practices have a proven record of usefulness in the minds of interviewees. Therefore, interviewees perhaps ignored this factor as it may not be an issue for PM discipline. 'Causal ambiguity or uncertainty' and 'relationship between the source of the knowledge and the adopter', were identified by Szulanski (1996) as two major barriers to the transfer of new practice, but these two factors were not highlighted by any interviewee.

\section{Conclusion}

The theoretical contribution of the research reported in this paper is twofold. Firstly, this research builds knowledge in the area of embedding PM, for which there is limited understanding (Cranefield and Yoong, 2009). Even the word 'embedding' is scarcely used in PM literature, perhaps because there is a common notion that if an organisation is improving its PM practices such PM practices must be successfully embedded in the organisation. However, this research conceptualises and provides empirical evidence that improving and embedding are different constructs.

Secondly, the research formulates an embedding construct by adopting an "innovation lens" perspective that draws on existing knowledge about diffusion, dissemination, implementation and routinisation, and by considering how these ideas may apply to the embedding of PM practice construct. Most of the literature on diffusion of innovation has treated innovations as technology innovations and makes heavy use of a technology adoption perspective focused on adopter related factors (Chan and Thong, 2009). However, this research has identified other important factors beyond adopter related factors related to: inner context; outer context; communication and influence; implementation; and routinisation. By incorporating a more diverse group of factors into the framework, the 
Table 6

Key embedding factors in the 'revised framework'.

\begin{tabular}{|c|c|c|c|c|}
\hline Theme & & 'Revised framework' & $\%$ & Comments \\
\hline $\begin{array}{l}\text { Adopter } \\
\text { adoption }\end{array}$ & and & 'Perceived usefulness' & $47 \%$ & $\begin{array}{l}\text { Confirmed. The factor 'relative advantage' was merged into the factor 'perceived usefulness', because the } \\
\text { interviewees concern was if the 'relative advantage' was perceived by the adopter, the initiative may have } \\
\text { benefits, but if it is not perceived there is no worth. 'Relative advantage' is sine qua non for adoption } \\
\text { (Greenhalgh et al., 2004). For example, interviewee } 30 \text { affirmed "If after implementation, project managers } \\
\text { do not experience the benefits of its use, they end up abandoning the practice use." }\end{array}$ \\
\hline
\end{tabular}

'Perceived ease of use' $\quad 40 \%$ Confirmed. Two new factors identified from interviewees: 'frequency of use' and 'quick use' of PM practices, after careful analysis were seen as explicative variables for the more general factor 'perceived ease of use'.

The factor 'complexity' was also merged into this more general factor 'perceived ease of use'. 'Complexity' was just directly prompted by two interviewees. Interview 14 has affirmed the importance of "...low complexity, simplicity, i.e., easy to use, objective, intuitive and appealing." Besides, complexity, as suggested by Venkatesh and Bala (2008), is one of the explicative variables of 'perceived ease of use'.

'Adopter motivation' $\quad 17 \%$ Confirmed. In line with Szulanski (1996) findings, contrary to conventional wisdom that places primary blame on motivational factors, adopter motivation it was only raised by five interviewees.

'Predisposition for change' $33 \%$ New. Two interviewees strongly emphasised 'predisposition for change', stressing the importance of people's attitude to change, that unfortunately, there are many professionals who are simply averse to change.

This is largely caused by individuals wishing to retain their own identity and do things 'their way' rather than conform to an imposed standard (Wang and Liu, 2007). As argued by Ward (2004) the parochial self-interest of individuals in maintaining the status quo. Ward (2004) points other individual issues (also related to resistance to change), such as: the inability to perceive a need for change; concerns that they will be unable to carry out the new practices (lack of skills); and the uncertainty and suspicion about the nature of the change. As argued by Loo (2002) some managers and staff are simply not prepared to change or not seeing a need to change. The individualism can be managed and its effects harnessed, namely, through the encouragement of employee participation, and the development of an understanding of organisational PM practices among all project stakeholders (Clarke, 1999).

'Nature of adoption 20\% Confirmed. Although, Greenhalgh et al. (2004) argued that generally, authoritative (mandatory) decisions decision - mandatory' for adoption may reduce in long term the chance that the innovation is successfully implemented and routinised. Interviewees asserted the importance of the 'imposition' for the use of the new practice. However, when mentioned this factor, some interviewees followed with some assertions about the importance of demonstrating the benefits of the new PM practice to adopters. Important to note, that if the nature of adoption decision of a PMII is mandatory as opposed to optional, it demonstrates sponsorship.

Inner Context 'Resources to support change'

$60 \%$ Confirmed/Discredited. In the 'initial framework' identified as 'structure of organisation and resources to support change', part of the factor was confirmed 'resources to support change' by $60 \%$ of interviewees, but the part 'structure of the organisation' was discredited. 'Structure of the organisation' includes several characteristics of the structure of the organisation such as: large (size); mature (organisation with a history of successful change, e.g. an organisation with a high PM maturity level); functionally differentiated (i.e. divided into semi-autonomous departments); and specialised (with foci of professional knowledge); if it has decentralised decision making structures (not formal structure), which were identified in literature as facilitators to embed new PM practices (NHS Modernisation Agency, 2003; Greenhalgh et al., 2004). However, from all these characteristics interviewees only mentioned the importance of the organisation's 'PM maturity', prompting that an organisation with the high level of PM maturity would more easily embed a new PM practice. Therefore, 'structure of the organisation' was discredited and a new factor emerged from this factor 'PM maturity' described below.

'Sponsorship' $\quad 40 \%$ New. It was emphasised by almost half of the interviewees. Therefore, it was separated from the more general factor 'receptive context for change' described in literature by several characteristics: sponsorship, clear strategic vision, good managerial relations, visionary staff in key positions, a climate conducive to experimentation and risk-taking, and effective monitoring and feedback systems (Greenhalgh et al., 2004; Englund and Bucero, 2006; Kerzner, 2009). Other variables inside of 'receptive context for change' were not identified by interviewees. Therefore, interview analysis led to the understanding that the factor 'receptive context for change', identified in the 'initial framework', has lower relevance than one of their explanatory characteristic. As such, the original key factor was removed from the framework (discredited) and replaced by the relevant characteristic 'sponsorship' emphasised by the interviewees.

'PM maturity'

'Tension for change'

'Absorptive capacity for new knowledge'

Outer Context
'External stakeholder requirement'
$20 \%$ New. 'PM maturity' was emphasised by some interviewees and so it was separated from the more general factor 'structure and resources to support change'. The embedment of the new PM practice is more likely if the organisation already has a high level of PM maturity.

$27 \%$ Confirmed. In the 'initial framework' identified as 'readiness for change', which is recognised as a more general factor. However, the aspect interviewees emphasised was just 'tension for change'. Therefore, it was slightly rephrased to 'tension for change'.

$13 \%$ Confirmed.

23\% Confirmed. Usually interviewees stated specifically a client's requirement and therefore the researchers narrow the factor, initially identified as 'external mandates', and slightly rephrased to 'external stakeholder requirement', commonly linked to client but could be an external sponsor, associate or supplier. 
Table 6 (continued)

\begin{tabular}{|c|c|c|c|}
\hline Theme & 'Revised framework' & $\%$ & Comments \\
\hline & $\begin{array}{l}\text { 'Informal } \\
\text { interorganisational } \\
\text { networks' }\end{array}$ & $3 \%$ & $\begin{array}{l}\text { Confirmed. An important influence on an organisation's decision to adopt is whether a threshold proportion } \\
\text { of comparable (homophilous) organisations have implemented or plan to implement improvement initiatives } \\
\text { (Greenhalgh et al., 2004; Carayon, 2010). Although only identified by one interviewee, when } \\
\text { 'interorganisational PM practices' were mentioned by the interviewer, 54\% of the interviewees agreed } \\
\text { with its significance. Interviewee } 15 \text { observed "If there are many people using, all people talk about it } \\
\text { because it works. At least, it will stimulate people's curiosity to their use." However, as one interviewee } \\
\text { asserted, this is a factor that facilitates implementation, but does not facilitate routinisation. If after } \\
\text { implementation, the adopter does not experience the benefits of its use, sooner or later he/she abandon the } \\
\text { practice use. Most of the interviewees that did not agree that 'interorganisational PM practices' was a key } \\
\text { embedding factor affirmed that what is really important are the PM practice benefits, rather than whether it is } \\
\text { used by other organisations. }\end{array}$ \\
\hline
\end{tabular}

'Unstable economic environment'

'Environmental culture'

Communication and influence

'Demonstrating the PMII value'

'Stakeholders involvement'

'Opinion leaders and key support facilitators'

Implementation

$10 \%$ New. Although 'unstable economic environment' was not identified as a key factor from literature review, $10 \%$ of the interviewees mentioned it. An unstable economic environment provokes a tension for change, in order to make the organisation more competitive. As such, an 'unstable economic environment' increases the likelihood of embedding new PM practices.

$10 \%$ New. During the literature review environmental variables did not stand out as important factors. Nevertheless, $10 \%$ of the interviewees emphasised that if the organisation is inserted in an external environment where there is a PM culture, for example, this would facilitate organisations to embed PMIIs in the future.

97\% Confirmed. It was the most stated factor. The factor 'observability', previously identified in the 'initial framework' as PMII attribute, was merged into this more general factor. Demonstration of a PMII value would be facilitated if the benefits of an initiative are visible to adopters. Interviewee 2 asserted "The benefits need to be easily assimilated, and for that they need to be visible, self-evident, and self-explanatory."

$20 \%$ Confirmed. Initially named as 'adopter involvement'. However, after careful interview analysis, the early involvement in the implementation process should not be only of by adopter, but by all relevant stakeholders. Consequently, it was slightly rephrased to 'stakeholders involvement'.

$27 \%$ Confirmed. Initially identified as just 'opinion leaders', it was slightly rephrased to include 'key support facilitators' which would help on the routine use of new PM practices.

$47 \%$ New. 'Piloting' is closely related to the factor 'trialability', a PMII attribute previously identified in the 'initial framework' and merged into this factor.

Interviewees were not concerned if the PM practice has the 'trialability' attribute, i.e. if the practice could be trial on a limited basis, but if in the implementation process the practice is piloted in order to be customised to the specific user needs and also to demonstrate the PM practice benefits. Nevertheless, to pilot a new PM practice it must have the attribute 'trialability'.

'Piloting' is one of the six-stage approach from (Shehu and Akintoye, 2009) to implement and practice programme management. The stages include: awareness; understanding; planning; piloting; implementation; and consolidation and customisation.

'Gradual implementation' $33 \%$ New factor mentioned by a third of interviewees, who recognised that making change takes time and needs to be implemented in the 'right time'. For example, interviewee 27 observed: "Gradual implementation [is necessary] in order to better manage the expectations and benefits of implementation." Additionally, the knowledge required under different PMIIs is diverse. This diversity in PMIIs knowledge base might hinder the embedment of PMIIs (Greenhalgh et al., 2004), since the individuals' absorptive capacity for new knowledge is limited.

'Specific training'

$50 \%$ Confirmed. Training associated to new PM tasks and new working methods. This embedding factor is closely related to the PMII 'provide PM training'. However, as a PMII, in the framework, is indicating the necessity for organisations to provide PM training, in order to guarantee the PM competences necessary to manage their projects, whereas an embedding factor, in the framework, is indicating that when organisations are implementing a new PM practice should give the necessary specific training to resources to become able to its effective use.

'Adaptation/ Re-invention' 33\% Confirmed. Initially identified in the 'initial framework' as a PMII attribute 're-invention', it was slightly rephrased to 'adaptation/ re-invention'. Interviewees have emphasised that during the implementation process is important to adapt the PMIIs to suit their specific needs, this is more than a PMII attribute (capable of adaptation, refinement or modification), is something that during the implementation process must happen. Therefore, it was re-categorised under the theme 'implementation'. For example, Milosevic and Patanakul (2005) argue that organisations engaged in standardising PM tools should start off adapt the templates for use in a specific project.

'Integration with the existent practices'

$17 \%$ New. 'Integration with the existent practices' is closely related to the factor 'compatibility', a PMII attribute previously identified from literature and merged into this factor. Interviewees were not worried if the practice has the 'compatibility' attribute, but if in fact the organisation makes the integration of the PMII with the existent practices. A practice might be compatible with organisational norms values and ways of working, but if there is no effort to an effective integration, this attribute does not have any advantage. However, to integrate with the existent practices the PMII must have the attribute 'compatibility'.

This embedding factor is closely related to the PMII 'integrate the PM system with the general management 
Table 6 (continued)

\begin{tabular}{|c|c|c|c|}
\hline Theme & 'Revised framework' & $\%$ & Comments \\
\hline \multirow{5}{*}{ Routinisation } & & & $\begin{array}{l}\text { system', showing how closes the concepts of improving and embedding are. However, as a PMII, in the } \\
\text { framework, it is indicating to organisations the necessity to embrace a PMII guaranteeing that the entire PM } \\
\text { system is integrated with the general management system, whereas an embedding factor, in the framework, } \\
\text { is indicating that when organisations are implementing a new PM practice they should integrate it with the } \\
\text { other existent practices in the organisation. }\end{array}$ \\
\hline & 'External collaboration' & $13 \%$ & $\begin{array}{l}\text { Confirmed. In the 'initial framework' identified as 'effective change agents', it was rephrased to 'external } \\
\text { collaboration'. Literature review indicated that if a 'change agent' is part of the PMII, the likelihood of a } \\
\text { successful PMII embedment increases (Greenhalgh et al., 2004). Controversially, when interviewees } \\
\text { mentioned about 'change agents', they stated the importance of an external collaboration, as one interviewee } \\
\text { affirmed "The participation in the implementation process of someone outside the organisation is crucial. } \\
\text { However, it does not dismiss an internal sponsorship, of someone internally responsible for the practice } \\
\text { dissemination, for the change management, who knows well the organisation." - (interviewee 6). In fact, } \\
\text { Menon and Pfeffer (2003) found that organisational members are more likely to value knowledge from } \\
\text { external than from internal sources. }\end{array}$ \\
\hline & $\begin{array}{l}\text { 'Feedback on the PMIIs } \\
\text { impacts' }\end{array}$ & $53 \%$ & $\begin{array}{l}\text { Confirmed. Giving 'feedback on the PMII impacts' the organisation is 'demonstrating the PMII value' after } \\
\text { its implementation. These two factors are so strongly correlated, that the researchers have doubts in the } \\
\text { construction of the 'revised framework', if the factor 'feedback on the PMII impacts' should be merged. } \\
\text { However, they decided not to do it, as the two factors were intensely emphasised by interviewees and they } \\
\text { occur in two distinct phases of the embedding process. Interviewees affirmed that 'demonstrating the PMII } \\
\text { value' should take place before the new PM practice implementation and the 'feedback on the PMII impacts' } \\
\text { should be given systematically during its use. Therefore, the factor 'feedback on the PMII impacts' was } \\
\text { re-categorised under the new theme created 'routinisation'. }\end{array}$ \\
\hline & $\begin{array}{l}\text { 'PM quality assurance } \\
\text { process' }\end{array}$ & $27 \%$ & $\begin{array}{l}\text { New. In spite of the first author researcher's professional experience in applying this kind of PM quality } \\
\text { assurance processes in organisations, this factor had not been included in the "initial framework'. However, } \\
\text { as interviewee } 27 \text { affirmed: "It is essential to support the use of PM practices, through coaching and also } \\
\text { quality assurance, to guarantee that people are using the institutionalised practices." }\end{array}$ \\
\hline & 'Adopter accountability' & $23 \%$ & $\begin{array}{l}\text { New. Interviewees emphasised that if the project team does not use the institutionalised PM practices, they } \\
\text { should suffer some penalty. }\end{array}$ \\
\hline
\end{tabular}

research provides a more complete understanding of the embedding process of PMIIs.

The first stage of the research reported here involved developing an 'initial framework' of key PMIIs and key factors to embed PMIIs derived from the literature and the researchers' professional experience. This 'initial framework' comprised of 15 key PMIIs (Table 1) and 32 key embedding factors (Table 2), with PMIIs and factors categorised into themes based on the literature.

Subsequently, a 'revised framework' was constructed following an exploratory study consisting of thirty semi-structured interviews with specialists in different levels of the organisational hierarchy (directors, portfolio, programme managers, project managers, and team members), from seven Portuguese companies. The framework incorporates the initial factors listed in the 'initial framework' (Tables 1 and 2), suitably modified to reflect the alterations suggested from the interview responses. Analysis of this interview data served to:

(a) identify three new PMIIs (e.g. 'PM Professionalisation') and ten embedding factors (e.g. 'adopter accountability');

(b) confirm twelve PMIIs (e.g. 'develop a supported infrastructure') and sixteen embedding factors (e.g. 'external stakeholder requirement');

(c) merge into other PMIIs, three PMIIs (e.g. 'develop project categorisation'), and five embedding factors (e.g. 'relative advantage'); and (d) discredit eleven embedding factors (e.g. 'gender and age differences').

Overall these modifications resulted in a 'revised framework' with 15 PMIIs and 26 embedding factors (Tables 5 and 6).

At the beginning of the research conceptualisation, it was hoped that the research might come up with a relatively short list of relevant embedding factors on which professionals should focus their attention. However, the results of the empirical work show that embedding PMIIs is a complex issue, and cannot be reduced to a small list of factors. It may be argued that even the present list of embedding factors is not detailed enough.

The main contribution to practice is a comprehensive framework of PMIIs and embedding factors grouped into themes which can provide guidance to organisations interested in increasing their performance in the management of projects. The framework highlights the need for organisations to focus on a particular set of PMIIs that includes not just specific PM tools and techniques, but wider initiatives, such as the alignment of PM activities with the whole organisation's activities or the professionalisation of the project manager's role. Additionally, the framework incorporates a number of factors that can facilitate the embedding of PMIIs. These embedding factors are a broad set comprising not just adopterrelated factors, but also inner context-related factors, outer 
context-related factors, communication and influence-related factors, implementation-related factors, and routinisation-related factors. This set of facilitating factors indicates a set of levers that organisations can use to devise strategies to promote the embedding of PMIIs into their systems. However, there remains the question of what initiatives should organisations embed first and in what order. Organisations might select the initiatives that were emphasised by more interviewees, or select the ones that they feel more 'comfortable' to deal with faster. Under the same line of argument, professionals might be more aware of the embedding factors emphasised by more interviewees such as: 'demonstrating the PMII value' before the implementation process, have available the necessary 'resources to support change', and during the use of the initiative, give continuous 'feedback on improvement impacts' on the organisation.

Further research could be conducted to understand if there are some PMIIs that might usefully precede others. For example, 'develop awareness of PM value among all staff' might precede 'corporate standardisation and tailoring of PM processes', following the conceptualisation of Shi (2011) on the development of the Value Adding Path Map (VAPM) framework, which indicates the steps to implement PM. Also, if there are critical embedding factors, for example, if there is no adopter's 'perceived usefulness' or 'perceived ease of use' of the PMII, it may not be worth working on the enhancement of other factors, such as 'resources to support change' or 'sponsorship'. The results of exploratory studies such as this require replication. The case studies could be also used to empirically validate the explanatory power of the conceptual framework in different organisational contexts. Validating the framework through case studies will be very valuable, namely in understanding the weight that different organisations (industry, size, strategy, geographic location, project types) place on different PMIIs and factors in promoting the embedment of PM practice in organisations.

\section{Conflict of interest}

There is no conflict of interest.

\section{Acknowledgements}

This research was sponsored by the FCT — Fundação para a Ciência e a Tecnologia (SFRH/BD/65423/2009). The authors gratefully acknowledge the contributions of the thirty interviewees who participated in the study.

\section{References}

Abrahamson, E., Fairchild, G., 1999. Management fashion: lifecycles, triggers, and collective learning processes. Adm. Sci. Q. 44 (4), 708-740.

Anantatmula, V., 2008. The role of technology in the project manager performance model. Proj. Manag. J. 39 (1), 34-48.

Andersen, E., Vaagaasar, A., 2009. Project management improvement efforts creating project management value by uniqueness or mainstream thinking? Proj. Manag. J. 40 (1), 19-27.
Argote, L., McEvily, B., Reagans, R., 2003. Managing knowledge in organizations: an integrative framework and review of emerging themes. Manag. Sci. Special issue 49, 571-582.

Atkinson, R., Crawford, L., Ward, S., 2006. Fundamental uncertainties in projects and the scope of project management. Int. J. Proj. Manag. 24 (8), 687-698.

Barber, E., 2004. Benchmarking the management of projects: a review of current thinking. Int. J. Proj. Manag. 22 (4), 301-307.

Besner, C., Hobbs, B., 2008. Project management practice, generic or contextual: a reality check. Proj. Manag. J. 39 (1), 6-34.

Besner, C., Hobbs, B., 2013. Contextualized project management practice: a cluster analysis of practices and best practices. Proj. Manag. J. 44 (1), $17-34$

Bresnen, M., Marshall, N., 2001. Understanding the diffusion and application of new management ideas in construction. Eng. Constr. Archit. Manag. 8 (5/6), 335-345.

Bresnen, M., Goussevskaia, A., Sawn, J., 2004. Embedding new management knowledge in project-based organizations. Organ. Stud. 25 (9), $1535-1555$.

Burnes, B., 2004. Kurt Lewin and the planned approach to change: a reappraisal. J. Manag. Stud. (UK) 41 (6), 977-1003.

Burnes, B., Cooper, C., West, P., 2003. Organisational learning: the new management paradigm? Manag. Decis. 41 (5), 452-465.

Carayon, P., 2010. Human factors in patient safety as an innovation. Appl. Ergon. 41 (5), 657-665.

Chan, F., Thong, J., 2009. Acceptance of agile methodologies: a critical review and conceptual framework. Decis. Support. Syst. 46 (4), 803-814.

Chapman, C., Ward, S., 2011. How to Manage Project Opportunity and Risk Why Uncertainty Management can be a Much Better Approach Than Risk Management. John Wiley \& Sons Ltd., United Kingdom.

Clarke, A., 1999. A practical use of key success factors to improve the effectiveness of project management. Int. J. Proj. Manag. 17 (3), 139-145.

Cooke-Davies, T.J., 2001. Towards improved project management practice: uncovering the evidence for effective practices through empirical research. Thesis for Doctor Philosophy. Leeds Metropolitan University.

Cooke-Davies, T., Crawford, L., Lechler, T., 2009. Project management systems: moving project management from an operational to a strategic discipline. Proj. Manag. J. 40 (1), 110-123.

Cranefield, J., Yoong, P., 2009. Embedding personal professional knowledge in a complex online community environment. Online Inf. Rev. 33 (2), $257-275$

Crawford, L., Pollack, J., 2004. Hard and soft projects: a framework for analysis. Int. J. Proj. Manag. 22 (8), 645-653.

Crawford, L., Turner, J., Hobbs, B., 2006. Aligning capability with strategy: categorizing projects to do the right projects and to do them right. Proj. Manag. J. 37 (2), 38-51.

Dai, C., Wells, W., 2004. An exploration of project management office features and their relationship to project performance. Int. J. Proj. Manag. 22 (7), 523-532.

Easterby-Smith, M., Thorpe, R., Jackson, P., 2008. Management Research. Sage, Los Angeles.

Ebert, C., Man, J., 2008. Effectively utilizing project, product and process knowledge. Inf. Softw. Technol. 50 (6), 579-594.

Englund, R., Bucero, A., 2006. Project Sponsorship: Achieving Management Commitment for Project Success. John Wiley \& Sons, San Francisco.

Eskerod, P., Riis, E., 2009. Project management models as value creators. Proj. Manag. J. 40 (1), 4-18.

Fernandes, G., Ward, S., Araújo, M., 2013. Identifying useful project management practices: A mixed methodology approach. Int. J. Info. Syst. Proj. Manag. 1 (4), 5-21.

Geraldi, J., Rodney, T., Maylor, H., Söderholm, A., Hobday, M., Brady, T., 2008. Innovation in project management: voices of researchers. Int. J. Proj. Manag. 26 (5), 586-589.

Gray, D.E., 2004. Doing Research in the Real World. Sage, London.

Green, S.E., 2004. A rhetorical theory of diffusion. Acad. Manag. Rev. 29 (4), 653-669

Greenhalgh, T., Robert, G., Macfarlane, F., Bate, P., Kyriakidou, O., 2004. Diffusion of innovations in service organizations: systematic review and recommendations. Milbank Q. 82 (4), 581-629. 
Hobbs, B., Aubry, M., Thuillier, D., 2008. The project management office as an organizational innovation. Int. J. Proj. Manag. 26 (5), 547-555.

Johnston, D., Linton, J., 2000. Social networks and the implementation of environmental technology. IEEE Trans. Eng. Manag. 47 (4), 465-477.

Kerzner, H., 2009. Project Management Case Studies. 3rd ed. John Wiley \& Sons, Inc., New Jersey.

Kwak, Y., Anbari, F., 2009. Availability-impact analysis of project management trends: perspectives from allied disciplines. Proj. Manag. J. 40 (2), 94-103.

Loo, R., 2002. Working towards best practices in project management: a Canadian study. Int. J. Proj. Manag. 20 (2), 93-98.

Luu, V., Kim, S., Huynh, T., 2008. Improving project management performance of large contractors using benchmarking approach. Int. J. Proj. Manag. 26 (7), 758-769.

Malach-Pines, A., Dvir, D., Sadeh, A., 2009. Project manager-project (PM-P) fit and project success. Int. J. Oper. Prod. Manag. 29 (3), 268-291.

Martinsuo, M., Hensman, N., Artto, K., Kujalo, J., Jaafari, A., 2006. Project-based management as an organizational innovation: drivers, changes, and benefits of adopting project-based management. Proj. Manag. J. 37 (3), 87-97.

Maylor, H., Brady, T., Cooke-Davies, T., Hodgson, D., 2006. From projectification to programmification. Int. J. Proj. Manag. 24 (8), 663-674.

Menon, T., Pfeffer, J., 2003. Valuing internal vs. external knowledge: explaining the preference for outsiders. Manag. Sci. 49 (4), 497-513.

Meskendahl, S., 2010. The influence of business strategy on project portfolio management and its success - a conceptual framework. Int. J. Proj. Manag. 28 (8), 807-817.

Meyers, P., Sivakumar, K., Nakata, C., 1999. Implementation of industrial process innovations: factors, effects, and marketing implications. J. Prod. Innov. Manag. 16 (3), 295-311.

Milosevic, D., Patanakul, P., 2005. Standardized project management may increase development projects success. Int. J. Proj. Manag. 23 (3), 181-192.

Milosevic, D., Srivannaboon, S., 2006. A theoretical framework for aligning project management with business. Proj. Manag. J. 37 (3), 98-110.

Mir, F., Pinnington, A., 2014. Exploring the value of project management: linking project management performance and project success. Int. J. Proj. Manag. 32 (2), 202-217.

Morris, P., 1997. The Management of Projects. Thomas Telford, London.

Morris, M., Venkatesh, V., 2000. Age differences in technology adoption decisions: implications for a changing work force. Pers. Psychol. 53 (2), 375-403.

NHS Modernisation Agency, 2003. Spread and sustainability of service improvement: factors identified by staff leading modernisation programmes. Research Into Practice Report No. 4: Overview of Early Research Findings. Department of Health, London.

Nystrom, P., Ramamurthy, K., Wilson, A., 2002. Organizational context, climate and innovativeness: adoption of imaging technology. J. Eng. Technol. Manag. 19 (3-4), 221-247.

Pellegrinelli, S., Garagna, L., 2009. Towards a conceptualisation of PMOs as agents and subjects of change and renewal. Int. J. Proj. Manag. 27 (7), 649-656.

Project Management Institute, 2013. Organizational Project Management Maturity Model. Knowledge Foundation $\left(O P M 3^{\circledR}\right)$. 3rd ed. Project Management Institute, Inc., Newtown Square, Pennsylvania.

Qureshi, T., Warraich, A., Hijazi, S., 2009. Significance of project management performance assessment (PMPA) model. Int. J. Proj. Manag. 27 (4), 378-388.
Robson, C., 2002. Real World Research: A Resource for Social Scientists and Practitioner-Researchers. Blackwell, Oxford.

Rogers, E., 2003. Diffusion of Innovations. 5th ed. Free Press, New York.

Sense, A., 2007. Structuring the project environment for learning. Int. J. Proj. Manag. 25 (4), 405-412.

Sharma, S., Rai, A., 2003. An assessment of the relationship between ISD leadership characteristics and IS innovation adoption in organizations. Inf. Manag. 40 (5), 391-401.

Shehu, Z., Akintoye, A., 2009. Construction programme management theory and practice: contextual and pragmatic approach. Int. J. Proj. Manag. 27 (7), 703-716.

Shi, Q., 2011. Rethinking the implementation of project management: a value adding path map approach. Int. J. Proj. Manag. 29 (3), 295-302.

Sowden, R., Hinley, D., Clarke, S., 2010. Portfolio, Programme and Project Management Maturity Model (P3M3). ([Online]. Available: http://www. p3m3-officialsite.com/P3M3Model/P3M3Model.aspx. [Accessed: 8th January 2014]).

Standish Group International, 2009. Chaos Summary 2009: The 10 Laws of Chaos, International Standish Group. pp. 1-4 (Available: http://pt. slideshare.net/AccelerateManagement/chaos-summary-2009-the-standishgroup. [Accessed: 9th December 2012]).

Szulanski, G., 1996. Impediments to the transfer of best practice within the firm. Strateg. Manag. J. 17, 27-43.

Szulanski, G., 2000. The process of knowledge transfer: a diachronic analysis of stickiness. Organ. Behav. Hum. Decis. Process. 82 (1), 9-27.

Thomas, J., Mullaly, M., 2008. Researching the Value of Project Management. Project Management Institute, Inc., Newtown Square, PA.

Van de Ven, A., Polley, D., Garud, R., Venkataraman, S., 1999. The Innovation Journey. Oxford University Press, New York.

Venkatesh, V., 2000. Determinants of perceived ease of use: integrating control, intrinsic motivation, and emotion into the technology acceptance model. Inf. Syst. Res. 11 (4), 342-365.

Venkatesh, V., Bala, H., 2008. Technology acceptance model 3 and a research agenda on interventions. Decis. Sci. 39 (2), 273-315.

Venkatesh, V., Davis, F., 2000. A theoretical extension of the technology acceptance model: four longitudinal field studies. Manag. Sci. 46 (2), $186-204$.

Venkatesh, V., Morris, M., Sykes, T., Ackerman, P., 2004. Individual reactions to new technologies in the workplace: the role of gender as a psychological construct. J. Appl. Soc. Psychol. 34 (3), 445-467.

Wang, X., Liu, L., 2007. Cultural barriers to the use of Western project management in Chinese enterprises: some empirical evidence from Yunnan province. Proj. Manag. J. 38 (3), 61-73.

Ward, S., 2004. Risk Management Organization and Context. Witherbys Publishing, London.

Winter, M., Szczepanek, T., 2008. Projects and programmes as value creation processes: a new perspective and some practical implications. Int. J. Proj. Manag. 26 (1), 95-103.

Zhai, L., Xin, Y., Cheng, C., 2009. Understanding the value of project management from a stakeholder's perspective: case study of mega-project management. Proj. Manag. J. 40 (1), 99-109. 